\title{
Paronychia erecta
}

\section{squareflower}

\section{Caryophyllaceae}

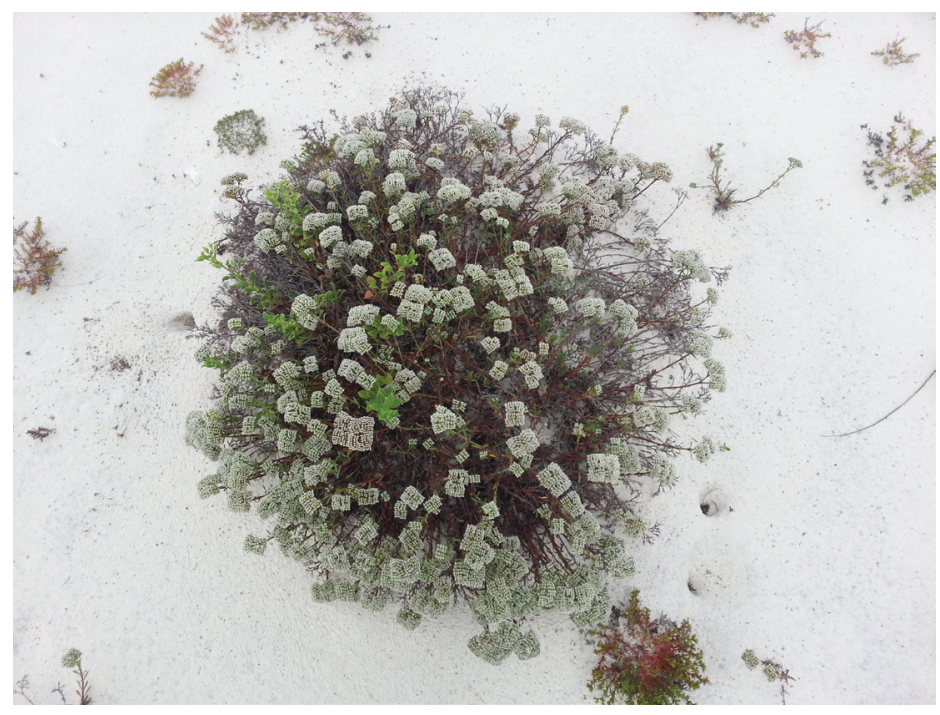

Credit: Gabriel Campbell, UF/IFAS

Squareflower is found in beach dunes, coastal grasslands, and scrub. This plant is an endemic restricted to the coastal Panhandle of Florida, counties west of the Big Bend region, and west to Louisiana. The square outline of the inflorescence is unique and makes squareflower a desirable plant for coastal landscapes.

\section{General Description}

Squareflower is a multiple stemmed, herbaceous perennial species with a short canopy. Leaves are purple to pink to green, opposite, and up to $3 \mathrm{~mm}$ wide with linear to oblong papery stipules that are $1 / 2$ to $1 / 4$ as long as the leaves. Stems are stout and round and curve upward. Inflorescences are multibranched corymbs branching with distinct regularity, which results in a characteristic branch pattern making the outline a square. Flowers are perfect, 2.5 to $3 \mathrm{~mm}$ long, and hypogynous, with 5 white sepals and no petals. They occur from March to November. Fruits are a single-seeded indehiscent utricle (achene).

\section{Propagation}

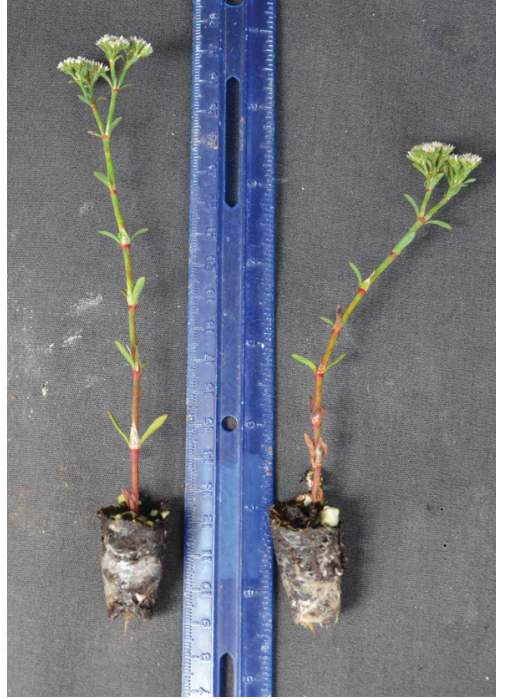

Credit: Gabriel Campbell, UF/IFAS
Auxin is not needed to initiate roots for stem cuttings of squareflower. The authors found wild collected apical stem cuttings (with or without floral buds) collected from late winter to late spring/ early summer root readily within 2 weeks under intermittent mist. Adventitious roots produced by cuttings are very fibrous (small in diameter) and delicate, and much care was required when removing rooted cuttings

from the propagation flats for transplanting to production containers. Plugs may require additional production time to allow sufficient root system formation and improvement of adventitious root connections to the cutting.

No published seed germination information is available for squareflower.

The authors found seeds collected in November and stored in the dark for 3 months in a greenhouse germinated readily within 2 weeks when placed on top of potting soil under intermittent mist with natural photoperiod in mid-February. A closely related species found in scrub (Paronychia chartacea subsp. chartacea) has been shown to not have seed dormancy (Stephens et al. 2012) but may require microorganisms (algae, lichens, cyanobacteria, mosses, fungi, and bacteria) within soil crusts to aid germination in the wild (Hawkes 2004). 


\section{Outplanting}

Production information for this species has only recently been refined; hence, the authors have had limited experience transplanting square flower to the coastal dunes. Square flower has been successfully transplanted in informal plantings when grown in 4-in pots within protected beach dune areas behind a primary dune ridge. No survival data were obtained, and further experience and information are needed to make an informed recommendation.

\section{Literature Cited}

Hawkes, C.V. 2004. "Effects of biological soil crusts on seed germination of four endangered herbs in a xeric Florida shrubland during drought." Plant Ecology. 170:121-134.

Stephens, E.L., L. Castro-Morales, and P.F. Quintana-Ascencio. 2012. "Post-dispersal seed predation, germination, and seedling survival of five rare Florida scrub species in intact and degraded habitats." American Midland Naturalist. 167:223-239.

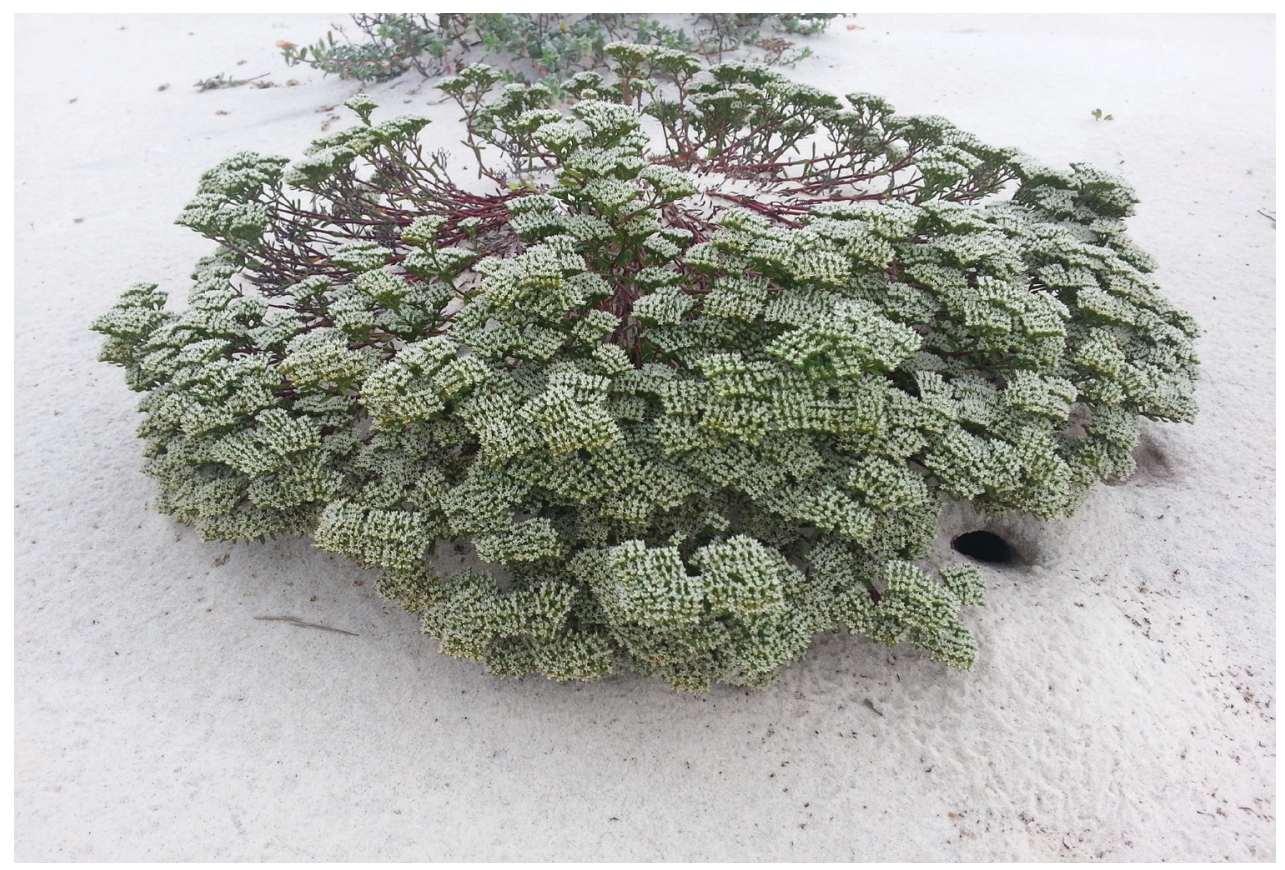

Credit: Gabriel Campbell, UF/IFAS 